\title{
Effects of Enhanced Hydrophilic Titanium Dioxide-Coated Hydroxyapatite on Bone Regeneration in Rabbit Calvarial Defects
}

\author{
Ji-Eun Lee ${ }^{1,+} \oplus$, Chung Wung Bark ${ }^{2,+} \oplus$, Hoang Van Quy ${ }^{2}$, Seung-Jun Seo ${ }^{1}$, Jae-Hong Lim ${ }^{3}$, \\ Sung-A Kang ${ }^{4}$, Youngkyun Lee ${ }^{5}{ }^{\mathbb{D}}$, Jae-Mok Lee ${ }^{1}$, Jo-Young Suh ${ }^{1}$ and Yong-Gun Kim ${ }^{1, *}$ \\ 1 Department of Periodontology, School of Dentistry, Kyungpook National University, Daegu 41940, Korea; \\ lufinel@naver.com (J.-E.L.); juns@knu.ac.kr (S.-J.S.); leejm@knu.ac.kr (J.-M.L.); jysuh@knu.ac.kr (J.-Y.S.) \\ 2 Department of Electrical Engineering, Gachon University, Seongnam 13120, Korea; \\ bark@gachon.ac.kr (C.W.B.); quybk20113989@gmail.com (H.V.Q.) \\ 3 Industrial Technology Convergence Center, Pohang Accelerator Laboratory, Pohang University of Science \\ and Technology (POSTECH), Pohang, Gyeongbuk 37673, Korea; limjh@postech.ac.kr \\ 4 Advanced Bio Convergence Center, Pohang Technopark, Pohang 37668, Korea; kang5239@ptp.or.kr \\ 5 Department of Biochemistry, School of Dentistry, Kyungpook National University, Daegu 41940, Korea; \\ ylee@knu.ac.kr \\ * Correspondence: periokyg@knu.ac.kr; Tel.: +82-53-600-7524 \\ + These authors contributed equally to this work.
}

Received: 12 October 2018; Accepted: 16 November 2018; Published: 19 November 2018

\begin{abstract}
The regeneration of bone defects caused by periodontal disease or trauma is an important goal. Porous hydroxyapatite (HA) is an osteoconductive graft material. However, the hydrophobic properties of $\mathrm{HA}$ can be a disadvantage in the initial healing process. $\mathrm{HA}$ can be coated with $\mathrm{TiO}_{2}$ to improve its hydrophilicity, and ultraviolet irradiation (UV) can further increase the hydrophilicity by photofunctionalization. This study was designed to evaluate the effect of $5 \% \mathrm{TiO}_{2}$-coated $\mathrm{HA}$ on rabbit calvarial defects and compare it with that of photofunctionalization on new bone in the early stage. The following four study groups were established, negative control, $\mathrm{HA}, \mathrm{TiO}_{2}$-coated $\mathrm{HA}$, and $\mathrm{TiO}_{2}$-coated $\mathrm{HA}$ with UV. The animals were sacrificed and the defects were assessed by radiography as well as histologic and histomorphometric analyses. At 2 and 8 weeks postoperatively, the $\mathrm{TiO}_{2}$-coated $\mathrm{HA}$ with UV group and $\mathrm{TiO}_{2}$-coated $\mathrm{HA}$ group showed significantly higher percentages of new bone than the control group $(p<0.05)$. UV irradiation increased the extent of new bone formation, and there was a significant difference between the $\mathrm{TiO}_{2}$-coated $\mathrm{HA}$ group and $\mathrm{TiO}_{2}$-coated $\mathrm{HA}$ with UV group. The combination of $\mathrm{TiO}_{2} / \mathrm{HA}$ and UV irradiation in bone regeneration appears to induce a favorable response.
\end{abstract}

Keywords: regeneration; calvarial defect; photofunctionalization; ultraviolet; titanium dioxide; hydrophilicity

\section{Introduction}

The regeneration of bone defects caused by infection or trauma is an important goal in clinical practice, and tissue engineering has been used to control the process of wound healing so that the tissue can be regenerated. The three crucial factors in tissue engineering are cells, scaffold (supporting matrices), and signaling molecules. In terms of the scaffold, hydroxyapatite (HA) is a bone material with osteoconductivity [1]. The porous structure of HA promotes the ingrowth of cells and microvessel growth leading to bone formation. Moreover, for this bone material, optimal pore sizes from 150 to $500 \mu \mathrm{m}$ are an important factor in forming new bone [2]. 
Even though the adhesion of osteoblast cells to the surface of a scaffold is a crucial factor for the healing of hard tissue, many materials, such as HA or titanium, have a disadvantage in the initial healing process because of their hydrophilicity. To solve this problem, previously, $\mathrm{TiO}_{2}$ and UV treatments of the surface of materials were adopted. For example, there is biocompatibility based on the formation of a thin $\mathrm{TiO}_{2}$ layer [3]. It has been reported that treatment of the surface of dental implants with $\mathrm{TiO}_{2}$ improves cell adhesion and osseointegration. Fujibayashi and his colleagues [4] reported in their study on porous titanium material that the complex interconnective macroporous structure improves osteoconductivity. However, titanium and these alloys have been reported to have disadvantages such as low tissue adherence and a degree of toxicity caused by release during corrosion [5,6]. Niska and her colleagues [7] demonstrated that toxicity induced by $\mathrm{TiO}_{2}$ nanoparticles cause oxidative damage by increasing levels of $\mathrm{O}_{2}{ }^{\bullet-}$ (superoxide anion) in human osteoblast cells. On the other hand, Mani et al. [8] reported in their in vivo study that hydroxyapatite attenuates the toxicity of $\mathrm{TiO}_{2}$. In addition, Okumura et al. [9] studied the initial attachment of osteoblast cells (Saos-2) to different materials, and they reported superior early adhesion of human osteoblast-like cells to HA and titanium than to other materials. Therefore, a combination of $\mathrm{HA}$ and $\mathrm{TiO}_{2}$ for bone regeneration is considered appropriate.

According to several reports on how the surface properties of dental implants improve osseointegration, titanium and these alloys do not show reliable bone-to-implant contact $[4,10]$. They concluded that modifying surface characteristics is necessary to improve osseointegration. Zhao and his colleagues [11] reported in their study that osteoblasts cultured on hydrophilic surfaces express higher levels of differentiation markers, such as alkaline phosphatase and osteocalcin and generated an osteogenic microenvironment. Ultraviolet (UV) photofunctionalization has been widely studied as a means to increase hydrophilicity to further improve the effect of a scaffold on bone formation [12-14]. Radiating the titanium surface with UV enhances the physical properties. One review reported that the unique alteration of the titanium surface after UV treatment is attributed to the surface of $\mathrm{TiO}_{2}$, which is changed to hydrophilic at the atomic level [13]. More specifically, UV irradiation of the titanium surface converts $\mathrm{Ti}^{4+}$ into $\mathrm{Ti}^{3+}$, which is beneficial for adsorption and makes the titanium surface bioactive by becoming hydrophilic. Thus, in several studies, UV photofunctionalization has been reported as a method for increasing cell attachment and new bone formation to this more hydrophilic surface $[12,15,16]$. The use of scaffold carriers with increased hydrophilicity is expected to further enhance the initial healing response for regeneration, including angiogenesis and osseointegration.

To reduce nanotoxicity due to nanosized $\mathrm{TiO}_{2}$ particles, we have attempted to lower the ratio of $\mathrm{TiO}_{2}$ by adding a surfactant. An in vitro pilot study indicated that a rapid change in terms of hydrophilicity occurs when concentration of nanosized $\mathrm{TiO}_{2}$ is varied from 1.5 to $5 \%$, as indicated by the change in the contact angle. Therefore, in this study, UV photofunctionalization was examined in $5 \% \mathrm{TiO}_{2}$ to determine the minimum dose. This experiment was designed to evaluate the effect of using $\mathrm{HA}$ with $5 \% \mathrm{TiO}_{2}$ on rabbit calvarial defect models as a bone graft material and to perform histologic and histomorphometric comparisons of the effect of ultraviolet photofunctionalization on new bone formation in the early phase of the healing response.

\section{Results}

\subsection{Surface Characteristics}

Figure 1a shows the XRD pattern of the $\mathrm{HA} / \mathrm{TiO}_{2}$ sample. The XRD analysis indicated that $\mathrm{TiO}_{2}$ adheres well to the HA surface. The low intensity of the $\mathrm{TiO}_{2}$ peak was thought to be due to the minimum concentration of $\mathrm{TiO}_{2}$ present in the mixture. The XRD peaks clearly indicate the HA and $\mathrm{TiO}_{2}$ phases and suggest that a mutual reaction between $\mathrm{HA}$ and $\mathrm{TiO}_{2}$ and decomposition did not occur because the calcination temperature was kept at only $450^{\circ} \mathrm{C}$. A sodium dodecylbenzenesulfonate (SDBS) peak was not observed because it had already been removed during the thermal annealing. Figure $1 \mathrm{~b}$ shows the FTIR spectrum of the $\mathrm{HA} / \mathrm{TiO}_{2}$ sample. The chemical groups of the HA particles 
in the FTIR spectrum are $\mathrm{PO}_{4}^{3-}, \mathrm{OH}^{-}$, and $\mathrm{CO}_{3}^{2-}$. The FTIR spectrum of the coatings clearly illustrates the low presence of both titania phases $\left(400-800 \mathrm{~cm}^{-1}\right)$ and the presence of HA. The FTIR analysis indicated that SDBS did not change the chemical composition of the $\mathrm{HA} / \mathrm{TiO}_{2}$ sample. The spectrum for SDBS did not appear, agreeing with the XRD measurement. The FTIR measurement confirmed that SDBS was volatilized after the sintering process. Using UV equipment and geometry (Figure 1c), UV light was used to irradiate the $\mathrm{HA} / \mathrm{TiO}_{2}$ sample. Figure $1 \mathrm{~d}$ presents the contact angle results of $\mathrm{HA} / \mathrm{TiO}_{2}$ coating after UV exposure. The sample showed superior wettability compared with the HA cases. The surface-prepared sample was easily wetted, resulting in a sharp decrease in the contact angle to nearly $0^{\circ}$.
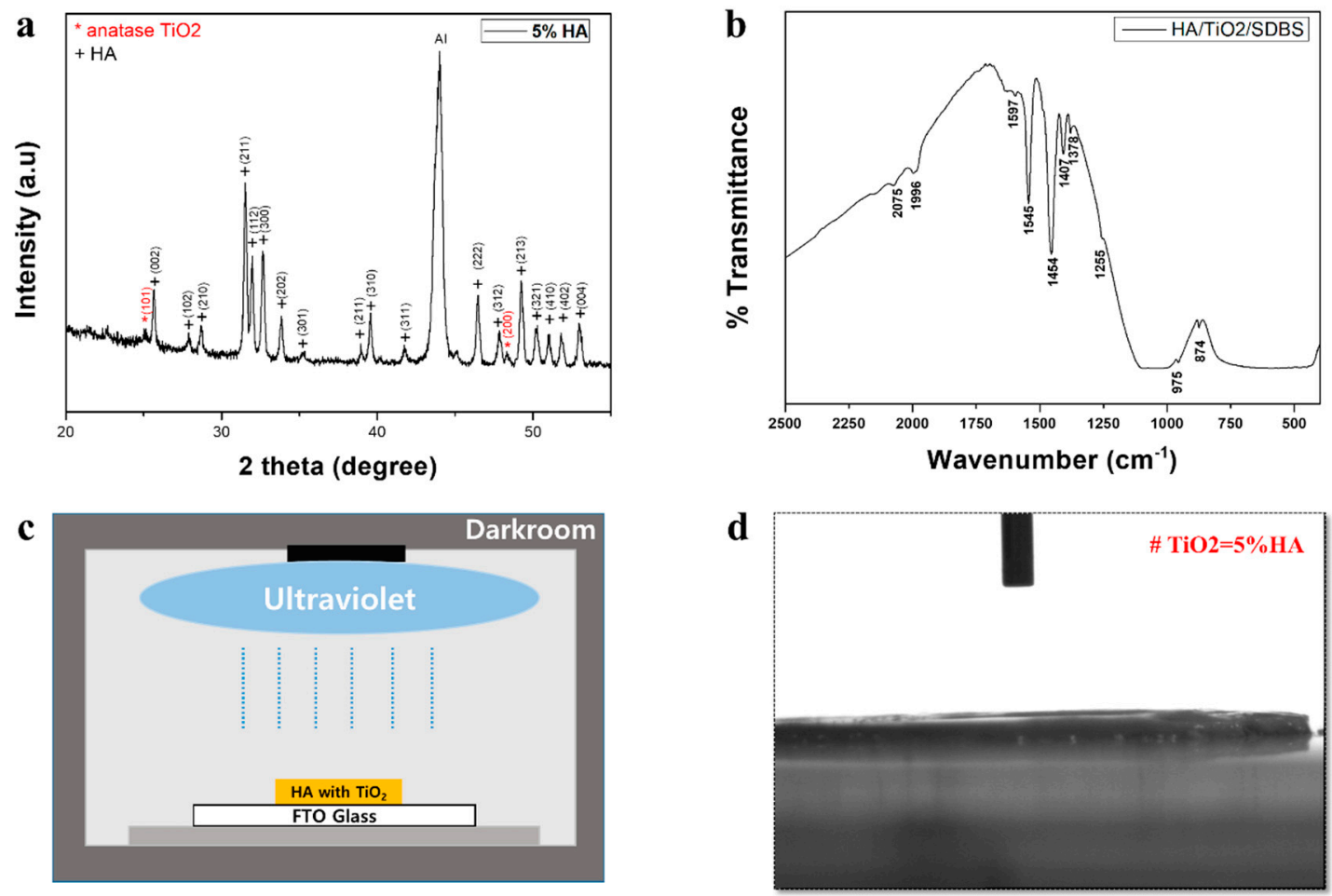

Figure 1. (a) X-ray diffraction spectroscopy (XRD) analysis. Anatase $\mathrm{TiO}_{2}$ is present in $\mathrm{TiO}_{2}$-coated HA. (b) Fourier transform infrared spectroscopy (FTIR) measurement to check the biocompatibility of the combined graft material. (c) Photofunctionalization of $\mathrm{TiO}_{2}$-coated $\mathrm{HA}$ particles by irradiating with ultraviolet light for $1 \mathrm{~min}$ using a photo device. (d) Wettability test. For the $5 \% \mathrm{TiO}_{2}$ sample in the mixture, the contact angle was maintained at $0^{\circ}$.

\subsection{Histology}

All animals survived the surgical procedure, and the clinical healing process was uneventful, without postoperative complications such as surgical wound dehiscence, signs of inflammation, edema, or other complications. Six rabbits were sacrificed two weeks after surgery, and the remaining six rabbits were sacrificed after eight weeks.

At two weeks, most of newly formed bone was woven bone with large numbers of osteoclasts, as shown in Figure 2. Bone regeneration appeared to extend from the border of the surgical defect to the center. $\mathrm{TiO}_{2}$ was observed as a black-colored particle in the $\mathrm{TiO}_{2}$-coated $\mathrm{HA}$ group and $\mathrm{TiO}_{2}$-coated HA with UV group. In contrast to the negative control group, in which little newly formed bone was observed, woven bone formed around the bone graft materials in the three other groups (Figure 2a). In Masson trichrome staining, the immature woven bone was stained blue, and abundant and dense immature bone was clearly observed in the $\mathrm{TiO}_{2}$-coated HA with UV group (Figure $2 \mathrm{~b}$ ). 

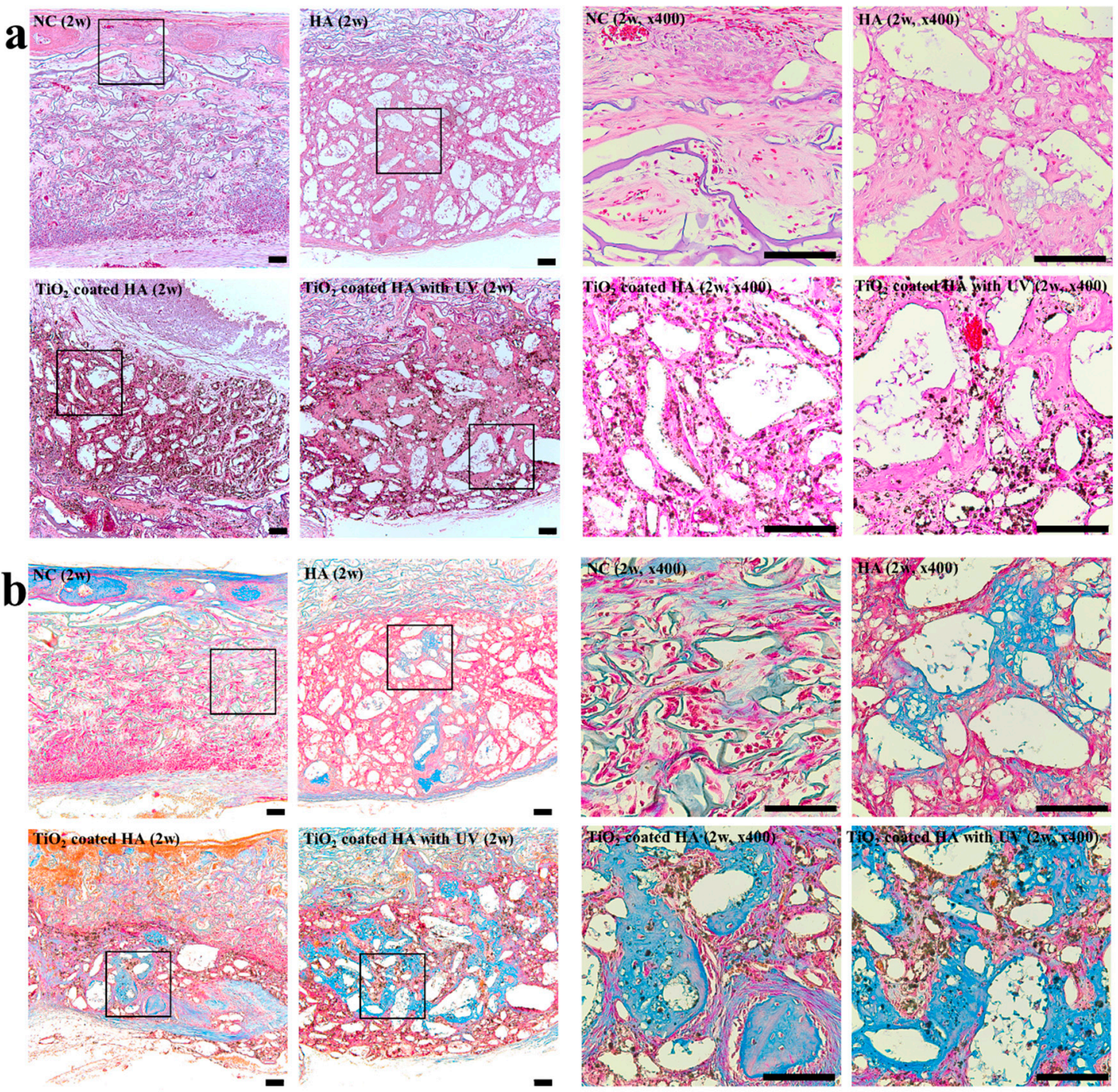

Figure 2. Histological findings (2 weeks). (a) Left: Light microscopy using hematoxylin and eosin $(\mathrm{H} \& \mathrm{E})$ stain $(\times 100)$ showing new bone formation in the groups at two weeks postoperatively; $\mathrm{NC}$ group, $\mathrm{HA}$ group, $\mathrm{TiO}_{2}$-coated $\mathrm{HA}$ group, and $\mathrm{TiO}_{2}$-coated $\mathrm{HA}$ with UV group. In UV-treated group (lower-left), there was significantly more newly formed bone than in the other groups. Right: Magnification of (a) $(\times 400)$. Scale bar: 100 um; (b) Left: Light microscopy using Masson trichrome stain $(\times 100)$ showing new bone formation in the groups at two weeks postoperatively; NC group, HA group, $\mathrm{TiO}_{2}$-coated HA group, and $\mathrm{TiO}_{2}$-coated HA with UV group. In the UV-treated group (lower-left), the residual graft materials were surrounded by blue-colored woven bone. Right: Magnification of (b) $(\times 400)$. Scale bar: $100 \mathrm{um}$.

Histologic analysis of new bone formation at 8 weeks (Figure 3a,b) revealed that the amounts of new bone in the surgical defect increased in all groups compared with that at two weeks. We also observed more mature bone with moderate amounts of the bone marrow. At eight weeks, most of the defects in the $\mathrm{TiO}_{2}$-coated HA with UV group were filled with new bone. 

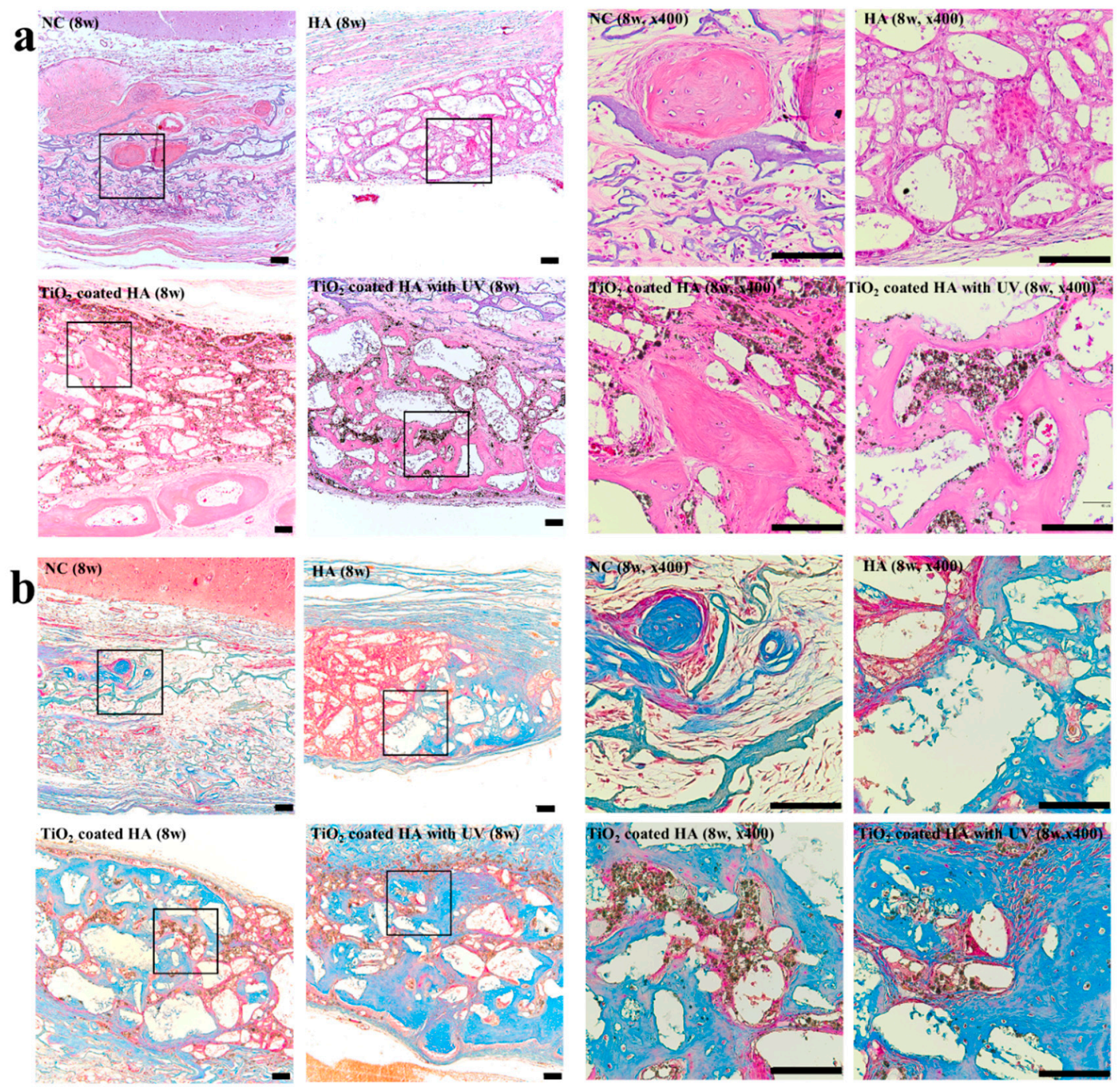

Figure 3. Histological findings (eight weeks). (a) Left: Light microscopy using H\&E stain $(\times 100)$ showing new bone formation in the groups at eight weeks postoperatively; NC group, HA group, $\mathrm{TiO}_{2}$-coated HA group, and $\mathrm{TiO}_{2}$-coated $\mathrm{HA}$ with UV group. The amount of new bone formation in all groups was greater than that at 2 weeks after surgery. New bone formation in the $\mathrm{TiO}_{2}$-coated $\mathrm{HA}$ with UV group was more distinct than that in the other groups. Right: Magnification of $(\mathbf{a})(\times 400)$. Scale bar: $100 \mathrm{um}$. (b) Left: Light microscopy using Masson trichrome stain $(\times 100)$ showing new bone formation in the groups at 8 weeks postoperatively; $\mathrm{NC}$ group, $\mathrm{HA}$ group, $\mathrm{TiO}_{2}$-coated $\mathrm{HA}$ group, and $\mathrm{TiO}_{2}$-coated HA with UV group. UV-treated group (lower-left). Right: Magnification of (b) $(\times 400)$. Scale bar: $100 \mathrm{um}$.

\subsection{Histomorphometry}

The measured value of the degree of new bone formation gradually increased over time. As shown in Figure 4 and Table 1, there was a significant difference between two and eight weeks in all four groups. In the evaluation of the residual bone material percentage, only the $\mathrm{TiO}_{2}$-coated $\mathrm{HA}$ group showed a significant difference between two and eight weeks after the surgery $(p<0.05)$. 


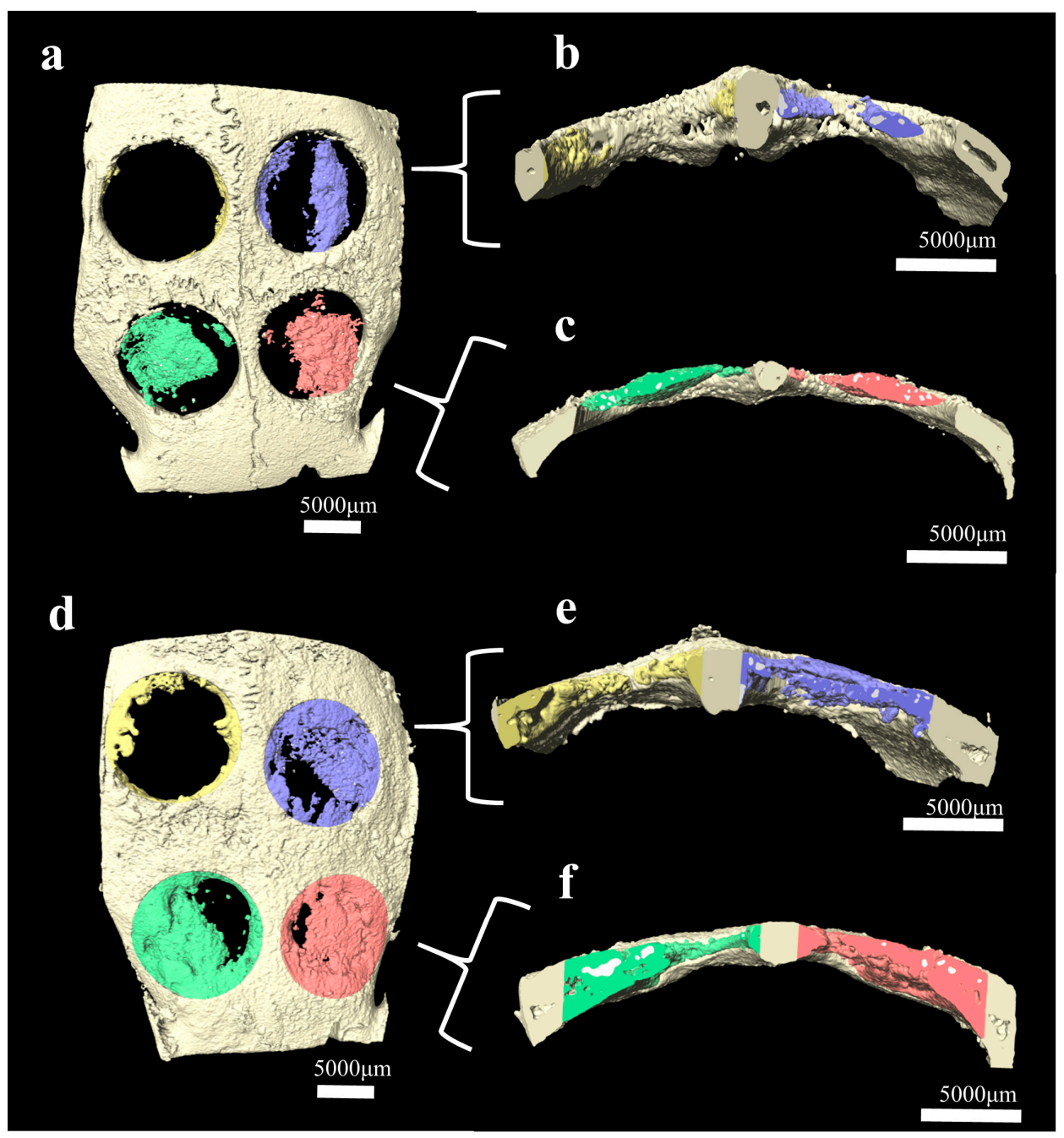

Figure 4. Comparison of regenerated new bone volume at 2 weeks $(\mathbf{a}-\mathbf{c})$ and eight weeks $(\mathbf{d}-\mathbf{f})$ after surgery. The defects from the four groups are represented in different colors as follows: the NC group (yellow), HA group (blue), $\mathrm{TiO}_{2}$-coated $\mathrm{HA}$ group (green), and $\mathrm{TiO}_{2}$-coated $\mathrm{HA}$ with $\mathrm{UV}$ group (red). $3 \mathrm{D}$ visualization of a rabbit calvarial defect specimen acquired by micro-CT for $(\mathbf{a}, \mathbf{d})$ a whole specimen containing new bone and substitutes, $(\mathbf{b}, \mathbf{e})$ cross-section image of the NC group and HA group, and (c,f) cross-section image of the $\mathrm{TiO}_{2}$-coated $\mathrm{HA}$ group and $\mathrm{TiO}_{2}$-coated $\mathrm{HA}$ with UV group.

The percentages of new bone and residual bone material at two and eight weeks postoperatively are listed in Table 1 and Figure 5. These values of histologic and histomorphometric evaluations were done directly from the histologic slides. The newly formed bone ratios in the surgically created defect at two weeks after the surgery were $6.36 \pm 1.72 \%$ (NC group), $18.78 \pm 4.60 \%$ (HA group), $28.63 \pm 2.75 \%$ ( $\mathrm{TiO}_{2}$-coated $\mathrm{HA}$ group), and $36.32 \pm 6.87 \%\left(\mathrm{TiO}_{2}\right.$-coated $\mathrm{HA}$ with $\mathrm{UV}$ group), and the percentages of residual bone material were $10.56 \pm 1.62 \%$ (HA group), $10.90 \pm 1.78 \%$ ( $\mathrm{TiO}_{2}$-coated $\mathrm{HA}$ group), and $14.53 \pm 2.15 \%\left(\mathrm{TiO}_{2}\right.$-coated $\mathrm{HA}$ with $\mathrm{UV}$ group). The $\mathrm{TiO}_{2}$-coated $\mathrm{HA}$ with $\mathrm{UV}$ group had a significantly higher value of new bone formation than the three other groups, and there was a significant difference between the groups $(p<0.05)$. 


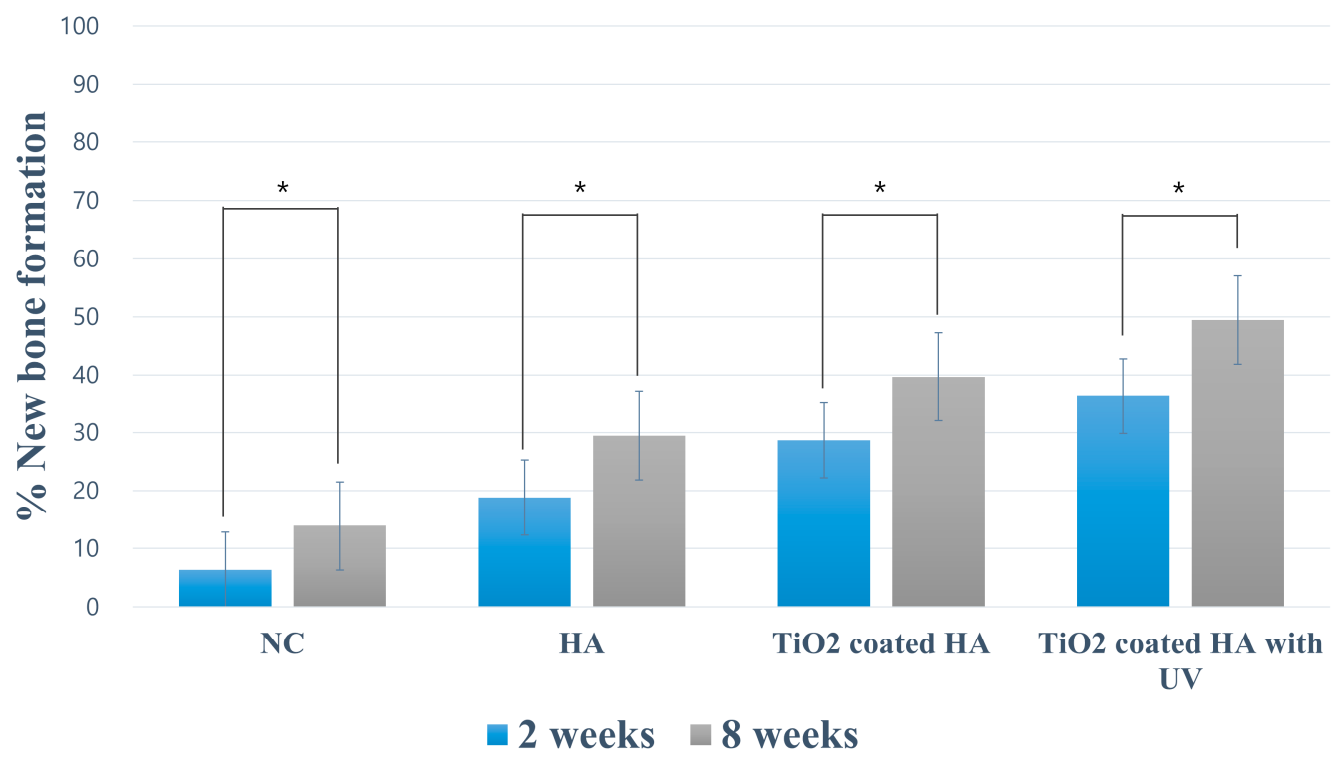

Figure 5. Histomorphometric evaluation of bone regeneration (intragroup analysis). In all groups, statistically significant intragroup differences in new bone formation were observed at two weeks and eight weeks. Data are presented as the mean \pm standard error of the mean. ${ }^{*} p<0.05$.

Table 1. Histomorphometry. Mean \pm standard deviation values for new bone (NB) and the residual bone material (RBM) as percentages within surgically created defects $(n=12)$.

\begin{tabular}{cccccc}
\hline & & Negative Control & Porous HA & TiO $_{2}$-Coated HA & TiO $_{2}$-Coated HA with UV \\
\hline \multirow{2}{*}{2 weeks } & $\% \mathrm{NB}$ & $6.36 \pm 1.72$ & $\begin{array}{r}18.78 \pm 4.60 \\
\mathrm{a}\end{array}$ & $28.63 \pm 2.75^{\mathrm{a}, \mathrm{b}}$ & $36.32 \pm 6.87^{\mathrm{a}, \mathrm{b}, \mathrm{c}}$ \\
& $\% \mathrm{RBM}$ & & $10.56 \pm 1.62$ & $10.90 \pm 1.78$ & $14.53 \pm 2.15^{\mathrm{b}}$ \\
\hline \multirow{2}{*}{8 weeks } & $\% \mathrm{NB}$ & $13.90 \pm 3.68$ & $\begin{array}{r}29.42 \pm 5.81 \\
\mathrm{a}\end{array}$ & $39.68 \pm 6.70^{\mathrm{a}, \mathrm{b}}$ & $49.46 \pm 6.54^{\mathrm{a}, \mathrm{b}, \mathrm{c}}$ \\
& $\% \mathrm{RBM}$ & & $12.14 \pm 5.22$ & $14.64 \pm 2.82$ & $13.38 \pm 3.44$ \\
\hline
\end{tabular}

NB: new bone, RBM: residual bone material. ${ }^{a}$ Statistically significant difference compared to the negative control group $(p<0.05) .{ }^{\mathrm{b}}$ Statistically significant difference compared to the HA group $(p<0.05)$. ${ }^{\mathrm{c}}$ Statistically significant difference compared to the $\mathrm{TiO}_{2}$-coated HA group $(p<0.05)$.

The newly formed bone ratio was $13.90 \pm 3.68 \%$ (NC group), $29.42 \pm 5.81 \%$ (HA group), $39.68 \pm 6.70 \%\left(\mathrm{TiO}_{2}\right.$-coated $\mathrm{HA}$ group), and $49.46 \pm 6.54 \%\left(\mathrm{TiO}_{2}\right.$-coated $\mathrm{HA}$ with UV group) at eight weeks postoperatively, and the $\mathrm{TiO}_{2}$-coated $\mathrm{HA}$ with UV group had a significantly higher new bone percentage than the three other groups $(p<0.05)$. The $\mathrm{TiO}_{2}$-coated $\mathrm{HA}$ group had significantly higher new bone formation than the NC and HA groups $(p<0.05)$. The remaining graft material ratios at 8 weeks were $12.14 \pm 5.22 \%$ (HA group), $14.64 \pm 2.82 \%\left(\mathrm{TiO}_{2}\right.$-coated $\mathrm{HA}$ group), and $13.38 \pm 3.44 \%$ ( $\mathrm{TiO}_{2}$-coated HA with UV group), and no difference between the groups was observed.

\section{Discussion}

The aim of this study was to compare the histological and histomorphometric evaluations of the degree of new bone formation in rabbit calvarial defects when applying $\mathrm{HA}$ with $5 \% \mathrm{TiO}_{2}$ and ultraviolet irradiation to induce bone formation. As mentioned above, the contact angle for the hydrophilicity evaluation changes according to the $\mathrm{TiO}_{2}$ concentration in $\mathrm{HA}$, and hence a concentration of $5 \% \mathrm{TiO}_{2}$ in $\mathrm{HA}$ was used in with or without the UV irradiation condition. Moreover, the defect size was $8 \mathrm{~mm}$, which is the critical size requiring additional treatment because the defect will not heal naturally during the life of the animal. Histologic evaluations at two and eight weeks were planned to examine the initial healing response $[17,18]$. 
Following the grafting of $\mathrm{HA}$ with $5 \% \mathrm{TiO}_{2}$, new bone formation was significant at the 2nd and 8th weeks of healing compared to that when only HA was applied. Specifically, the $\mathrm{TiO}_{2}$-coated $\mathrm{HA}$ group and UV treatment group had significantly more new bone formation at two and eight weeks compared with that in the HA only group. This indicated that the effect of $\mathrm{TiO}_{2}$ on new bone formation was stronger in the initial healing reaction. This may support the results of a study that reported that the nanoscale anodized titanium surface affects cell differentiation in the initial healing period, thus accelerating osseointegration and bone boding strength [19].

When new bone formation was compared between the $\mathrm{TiO}_{2}$-coated $\mathrm{HA}$ with UV group and $\mathrm{TiO}_{2}$-coated HA group, the percentage of new bone formation was significantly higher in the UV-irradiated group. The higher level of new bone formation in the UV-treated group was probably due to the electron excitation effect of the UV irradiation on $\mathrm{TiO}_{2}$ mentioned above. Shen et al. [14] investigated the effect of UV irradiation on the bone response in the tibial metaphyses and femoral condyle of rabbits in a histological and histomorphometric study. It had been reported that the nanostructure and UV treatment enhance the interfacial strength of titanium and intergranular bone to improve osseointegration. This conclusion is supported by the results of this experiment, despite the fact that different sites were evaluated, although the same experimental animals were used.

For this experiment, UV irradiation was performed for $1 \mathrm{~min}$. In many studies, longer UV exposure times result in a more hydrophilic surface because of photofunctionalization. M. Q. Tran and his colleague [20] reported that when irradiating with UV for $30 \mathrm{~min}$, the transition from a superhydrophobic to superhydrophilic state occurs faster than with $\mathrm{TiO}_{2}$ nanoparticle-coated samples. In addition, a superhemophilic pattern was observed in a wettability test on blood, indicating that the UV irradiation had a potential effect on the clinical application [21]. In a study of the photoinduced hydrophilicity effect, the water contact angle was $54.5^{\circ}$ for $\mathrm{TiO}_{2}$ film without any treatment and $29.3^{\circ}$ for $1 \mathrm{~min}$ of UV exposure [22]. For irradiation over $10 \mathrm{~min}$, the result was less than $5^{\circ}$, which indicates superhydrophilicity. However, when the initial healing response indicators such as fibrinogen adsorption and platelet adhesion/spreading were evaluated, there was no significant difference between $1 \mathrm{~min}$ and $10 \mathrm{~min}$ of UV irradiation; thus, it was concluded that further study was needed. Most other studies have reported that longer irradiation times result in a greater hydrophilic effect by photofunctionalization [15,23-25]. However, for clinical use, it is not appropriate to subject the patient to long treatment times, and hence we set a time of $1 \mathrm{~min}$ for this study. Additional studies on light irradiation methods will be needed to develop more appropriate clinical applications.

In this study, a heating technique was used to prevent $\mathrm{TiO}_{2}$ nanoparticles, which were coated homogeneously on the HA surface, from being separated. In other words, this heating technique, involving heating in a furnace to $450^{\circ} \mathrm{C}$, can prevent the separation phenomenon from occurring during the conventional method of mixing $\mathrm{TiO}_{2}$ nanoparticles with $\mathrm{HA}$ in ethanol solvent and stirring the mixture ultrasonically. Surface hydrophilicity was evaluated by assessing the contact angle and performing wettability tests, and SEM, XRD, and FTIR measurements were used to detect changes in surface morphology. It was confirmed in SEM and XRD analyses that $\mathrm{TiO}_{2}$ was adsorbed uniformly and stably on the surface of HA. Moreover, because SDBS was not present in the FTIR analysis, the biocompatibility of the corresponding sample might be guaranteed. Based on these results, this process was considered to be a suitable method for coating $\mathrm{TiO}_{2}$ nanopowder on porous HA.

However, the sample size of the $\mathrm{TiO}_{2}$-coated $\mathrm{HA}$ particles changed during the process of ultrasonic dispersion. The pore size of the commercial porous HA (Bongros; Daewoong Pharmaceutical Co. Ltd., Seongnam, Korea) was $300 \mu \mathrm{m}$, but the mixed graft material changed to a powder form during the stirring process; thus, the particle size and pore size may have decreased. In a study that evaluated the amount of new bone formation after applying various particle sizes of HA to temporal bullae in rats, larger HA particles were associated with faster new bone formation rates [26]. This finding explains why the rate of new bone formation was lower in this experiment when using a sample with smaller particle size than the rate reported in our previous study. Chang et al. studied the osteoconductivity of HA samples with various sizes of cylindrical pores, and they reported that active osteoconduction was 
also observed in HA with 50- $\mu \mathrm{m}$ cylindrical pores [27]. This can explain the osteoconductivity seen in this experiment, in which the pore size might have decreased. However, further studies on how this affected bone regeneration are needed before conclusions regarding the clinical evaluation and usefulness of the material can be made.

\section{Materials and Methods}

\subsection{Preparation of Bone Graft Materials}

Porous HA (Bongros; Daewoong Pharmaceutical Co. Ltd., Seongnam, Korea) was used for this study as a bone graft material. Sodium dodecylbenzenesulfonate (SDBS) was used as a surfactant to enhance the dispersibility of $\mathrm{TiO}_{2}$ nanoparticles on the HA surface. First, $0.2 \mathrm{~g}$ of SDBS was completely dissolved in $20 \mathrm{~mL}$ of deionized water, and $0.01 \mathrm{~g}$ of $\mathrm{TiO}_{2}$ nanoparticles was added to the solution under continuous stirring at $200 \mathrm{rpm}$ for $20 \mathrm{~min}$. Then, $0.2 \mathrm{~g}$ of $\mathrm{HA}$ and $\mathrm{TiO}_{2} / \mathrm{SDBS}$ powders, which were obtained from the centrifugation process, were thoroughly stirred into $20 \mathrm{~mL}$ ethanol for $20 \mathrm{~min}$. After that, heat treatment at $450^{\circ} \mathrm{C}$ for $3 \mathrm{~h}$ was applied to the mixture (mixing ratio: $\mathrm{HA} 0.2 \mathrm{~g}, \mathrm{TiO}_{2} 0.01 \mathrm{~g}$ ) to remove volatile SDBS.

The microscopic surface structures of porous $\mathrm{HA}$ and $\mathrm{TiO}_{2}$-coated $\mathrm{HA}$ were analyzed using scanning electron microscopy (SU8220, Hitachi High Technologies, Tokyo, Japan) following the platinum coating of the samples. The quantitative and qualitative measurements for the structural identification of the graft material compositions were performed using an energy dispersive $X$-ray spectrometer (X-ManN50 011; HORIBA, Kyoto, Japan).

\subsection{Wettability Test}

To evaluate hydrophilicity, a wettability test was performed to measure the contact angle of water droplets (interval time: $3 \mathrm{~min}$ ) with $\mathrm{HA}$ and a certain amount of $\mathrm{TiO}_{2}$ coated on $\mathrm{HA}$. All the procedures were carried out in a class 10 clean room under the conditions of $20^{\circ} \mathrm{C}$ and $46 \%$ humidity.

\subsection{UV Photofunctionalization}

Photofunctionalization was performed by irradiating the $\mathrm{HA}$ graft materials containing $\mathrm{TiO}_{2}$ with UV light in a dark room for $1 \mathrm{~min}$ using a photo device immediately before grafting. Specifically, the UV treatment was performed at room temperature for a fixed distance of $3 \mathrm{~cm}$ between the sample (the irradiated area on the sample was $2 \times 2 \mathrm{~cm}^{2}$ ) and the UV light source (UV radiation with a peak at $253.7 \mathrm{~nm}$, power: $8 \mathrm{~W}$ ).

\subsection{Animal Study}

Twelve New Zealand white rabbits weighing 2.7 to $3.2 \mathrm{~kg}$ were used in this study. The animals were fed a standard diet and housed in separate cages under standard laboratory conditions. This experiment, including animal selection, management, and the surgery protocol, was approved by the Institutional Animal Care and Use Committee of Kyungpook National University, Daegu, Korea (certification \#2017-0094; 05/07/2017). General anesthesia was induced by intramuscular injection of a mixture of zolazepam $(0.2 \mathrm{~mL} / \mathrm{kg}$; Zoletil, Virbac, Carros, France) and xylazine $(0.25 \mathrm{~mL} / \mathrm{kg}$; Rompun, Bayer Korea Co., Seoul, Korea). The surgical site was shaved and then covered with alcohol and povidone iodine. Complementary infiltrative anesthesia was administrated at the surgical site using $2 \%$ lidocaine with 1/100,000 epinephrine (1:100,000 epinephrine; Yuhan Co., Seoul, Korea) to control bleeding. The surgical site was exposed with a sagittal midline incision through the skin and the periosteum at the midline of the calvaria and a full-thickness flap elevation. Four standardized transosseous circular defects (of critical size: diameter $8 \mathrm{~mm}$ ) were prepared using a stainless steel trephine bur in the frontal and parietal bones of each animal under cool-saline irrigation (Figure 6a). 


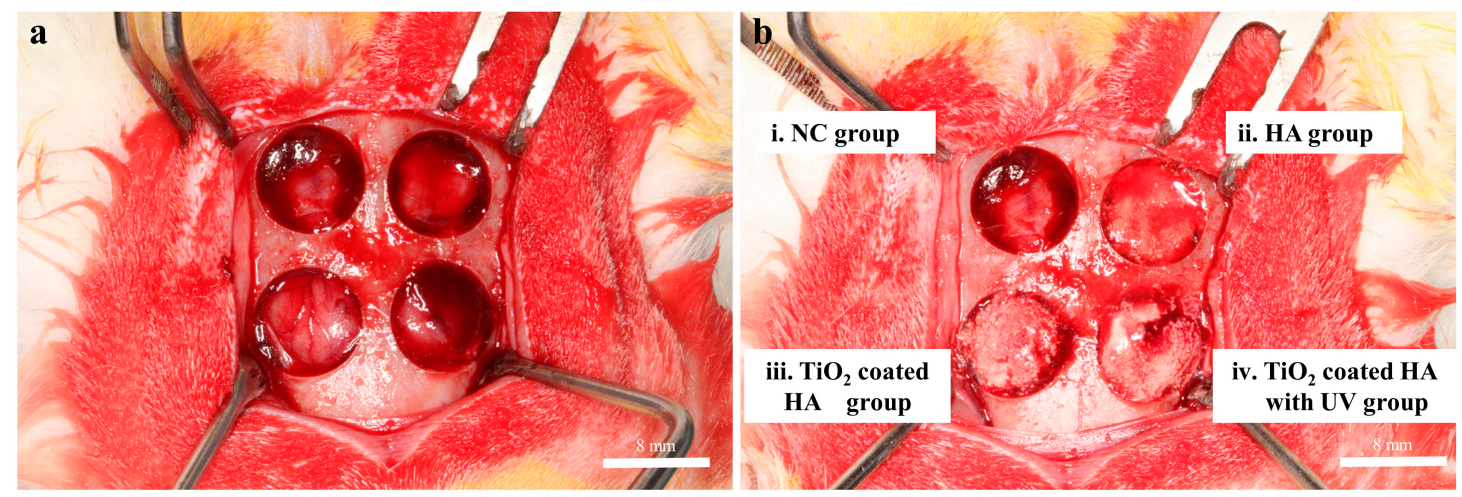

Figure 6. Clinical photographs of the experiment. (a) Photograph of four transosseous defects $8 \mathrm{~mm}$ in diameter, $>2 \mathrm{~mm}$ apart, that were created using a trephine bur in the each calvaria of 12 rabbits. (b) Defects were filled with the following graft materials. i. Unfilled as a negative control, NC group; ii. $0.025 \mathrm{~g}$ of $\mathrm{HA}, \mathrm{HA}$ group; iii. $0.025 \mathrm{~g}$ of $\mathrm{TiO}_{2}$-coated $\mathrm{HA}, \mathrm{TiO}_{2}$-coated $\mathrm{HA}$ group; and iv. $0.025 \mathrm{~g}$ of $\mathrm{TiO}_{2}$-coated $\mathrm{HA}$ with UV treatment for $1 \mathrm{~min}, \mathrm{TiO}_{2}$-coated $\mathrm{HA}$ with UV group.

Defects were filled with following graft materials (Figure 6b), $0.025 \mathrm{~g}$ of HA, HA group; $0.025 \mathrm{~g}$ of $\mathrm{TiO}_{2}$-coated $\mathrm{HA}, \mathrm{TiO}_{2}$-coated $\mathrm{HA}$ group; $0.025 \mathrm{~g}$ of $\mathrm{TiO}_{2}$-coated $\mathrm{HA}$, treated with UV for $1 \mathrm{~min}$, $\mathrm{TiO}_{2}$-coated HA with UV group; and the last defect was left unfilled as a negative control (NC), NC group. After surgery, surgical defects were covered with a resorbable collagen membrane (collatape; Zimmer, Carlsbad, CA, USA), and the soft tissues were closed in layers and sutured for primary closure using braided polyglycolic acid sutures (5-0 surgifit; AILEE, Busan, Korea) and Monofilament sutures (4-0 nylon; NYLON (blue); AILEE, Busan, Korea). Antibiotics (Baytril, Bayer Korea Co., Seoul, Korea) and analgesics (Nobin, Bayer Korea Co., Seoul, Korea) were injected intramuscularly for 3 days to control pain and prevent postsurgical infection as a postoperative management. Six animals were sacrificed by intravenous injections of air under general anesthesia at 2 weeks postoperatively, and the rest were sacrificed 8 weeks after the surgery. After sacrifice, the area of the surgical defect site and surrounding tissues were removed en bloc. These collected samples were fixed in $4 \%$ neutral-buffered paraformaldehyde.

\subsection{X-ray Microcomputed Tomography Analysis}

First, all en bloc samples were subjected to X-ray microtomography. This protocol micro-CT imaging was performed at the Pohang Center for Evaluation of Biomaterials, Pohang Technopark in Pohang, Korea, using a Siemens Inveon Trimodality Image system (INVEON; Siemens, Washington, DC, USA).

The CT slice images were reconstructed using Siemens Inveon Acquisition Workplace Software (INVEON; Siemens, Washington, DC, USA). CT Acquisition: For a whole body CT scan, set current at $500 \mathrm{uA}$, voltage at $80 \mathrm{kV}$, exposure time at $280 \mathrm{msec}$, and 180 steps for $360^{\circ}$ rotation. For X-ray detector, select resolution at "low system magnification" with $57.6 \mathrm{~mm}$ axial imaging field and single bed mode. We selected "real time reconstruction" using the "Common Cone-Beam Reconstruction" method so that the host PC talks with a dedicated real timereconstruction computer (Cobra) to initiate the task. The corresponding images, produced by stacking all cross-sectional images, create a map of the local X-ray attenuation coefficient plus the enhanced boundaries by the interference of transmitting coherent X-rays. Image analysis software (Amira Version 6.2; FEI Co., Hillsboro, OR, USA) was used for tridimensional (3D) visualization. In the image analysis, newly formed bone fragments were clearly distinguished from the HA in the gray level. Analysis of the 3D images allowed calculating the regenerated total volume of surgical defects and the extent of the newly formed radiopaque area at two weeks and eight weeks postoperatively. 


\subsection{Surface Characteristics and Histological and Histomorphometric Analyses}

For histological analysis, the fixed samples were decalcified in $10 \%$ ethylenediaminetetraacetic acid (EDTA) for 1 month and then embedded in paraffin. The paraffin-embedded tissues were cut from the center at 3- $\mu \mathrm{m}$ intervals using a Leica microtome (RM2245; Leica Microsystems, Bannockbrun, IL, USA), and the most central sections from each sample were subjected to hematoxylin-eosin (H\&E) and Masson's trichrome staining. Histological evaluations were performed by observing the stained sections under a microscope (Olympus BX53, Olympus, Tokyo, Japan) equipped with a $10 \times 0.30$ UPLANFL N objective lens (Olympus, Tokyo, Japan). Images were captured using a digital camera (Olympus, Tokyo, Japan) attached to the microscope. Histomorphometric analysis was performed using image analysis software (I-solution; iMTechnology, Daejeon, Korea) to calculate the amount of new bone ingrowth in the defect sites: (1) the percentage of new bone $(\%)=$ the area of new bone between the defect margins $\left(\mathrm{mm}^{2}\right) /$ the total augmented area $\left(\mathrm{mm}^{2}\right) \times 100(\%)$ and $(2)$ the percentage of residual bone material $(\%)=$ the area of residual bone material between the defect margins $\left(\mathrm{mm}^{2}\right) /$ the total augmented area $\left(\mathrm{mm}^{2}\right) \times 100(\%)$.

\subsection{Data Analysis}

Statistical analyses were conducted using IBM SPSS Statistics (SPSS Inc., Chicago, IL, USA). Statistical analyses included a nonparametric Kruskal-Wallis analysis of variance test to evaluate differences in the percentages of new bone formation and remaining bone particles. The Mann-Whitney U-test was used to evaluate the difference in bone regeneration between groups. Statistical significance was defined as a $p$-value less than 0.05 .

\section{Conclusions}

In this study, it was concluded that the combination of $\mathrm{TiO}_{2}$-coated $\mathrm{HA}$ and $\mathrm{UV}$ treatment for bone regeneration seems to be favorable to new bone formation. However, a comparative study to determine the optimal ratio of $\mathrm{TiO}_{2} / \mathrm{HA}$ as a bone material and $\mathrm{UV}$ irradiation time is needed.

Author Contributions: Conceptualization, Y.-G.K.; Methodology, Y.L., J.-H.L., S.-A.K., J.-M.L., J.-Y.S., and Y.-G.K.; software, Y.L., J.-H.L., S.-A.K., and Y.-G.K.; Validation, Y.-G.K.; Formal Analysis, J.-E.L., C.W.B., H.V.Q., S.-J.S., and Y.-G.K.; Resources, J.-E.L., C.W.B., H.V.Q., Y.L., J.-H.L., S.-A.K., J.-M.L., and Y.-G.K.; Data Curation, Y.L., J.-H.L., S.-A.K., and Y.-G.K.; Writing—original draft preparation, J.-E.L.; Writing—review and editing, Y.-G.K.; Visualization, J.-E.L., C.W.B., H.V.Q. and Y.-G.K.; Supervision, Y.-G.K.; Project Administration, Y.-G.K.; Funding Acquisition, Y.-G.K.

Funding: This research was supported by the Basic Science Research Program through the National Research Foundation of Korea (NRF) funded by the Ministry of Science, ICT \& Future Planning (NRF-2017R1C1B1009945).

Conflicts of Interest: The authors declare no conflict of interest.

\section{References}

1. Yang, S.; Leong, K.F.; Du, Z.; Chua, C.K. The design of scaffolds for use in tissue engineering. Part I. Traditional factors. Tissue Eng. 2001, 7, 679-689. [CrossRef] [PubMed]

2. Kim, R.W.; Kim, J.H.; Moon, S.Y. Effect of hydroxyapatite on critical-sized defect. Maxillofac. Plast. Reconstr. Surg. 2016, 38. [CrossRef] [PubMed]

3. Zane, A.; Zuo, R.; Villamena, F.A.; Rockenbauer, A.; Foushee, A.M.D.; Flores, K.; Dutta, P.K.; Nagy, A. Biocompatibility and antibacterial activity of nitrogen-doped titanium dioxide nanoparticles for use in dental resin formulations. Int. J. Nanomed. 2016, 11, 6459-6470. [CrossRef] [PubMed]

4. Fujibayashi, S.; Neo, M.; Kim, H.-M.; Kokubo, T.; Nakamura, T. Osteoinduction of porous bioactive titanium metal. Biomaterials 2004, 25, 443-450. [CrossRef]

5. Gonzalez, J.; Mirza-Rosca, J. Study of the corrosion behavior of titanium and some of its alloys for biomedical and dental implant applications. J. Electroanal. Chem. 1999, 471, 109-115. [CrossRef] 
6. Franchi, M.; Bacchelli, B.; Martini, D.; De Pasquale, V.; Orsini, E.; Ottani, V.; Fini, M.; Giavaresi, G.; Giardino, R.; Ruggeri, A. Early detachment of titanium particles from various different surfaces of endosseous dental implants. Biomaterials 2004, 25, 2239-2246. [CrossRef] [PubMed]

7. Niska, K.; Pyszka, K.; Tukaj, C.; Wozniak, M.; Radomski, M.W.; Inkielewicz-Stepniak, I. Titanium dioxide nanoparticles enhance production of superoxide anion and alter the antioxidant system in human osteoblast cells. Int. J. Nanomed. 2015, 10, 1095-1107. [CrossRef]

8. Mani, P.; Sharma, H.K.; Gautam, A.; Singh, T.; Verma, S.K.; Hussain, R. hydroxyapatite (HA) attenuate TiO2 toxicuty in bio-system triggering E. coli and mouse bone marrow mono nuclear cells (BMMNC'S). Int. J. Life Sci. Pharma Res. 2017, 7, L46-L57.

9. Okumura, A.; Goto, M.; Goto, T.; Yoshinari, M.; Masuko, S.; Katsuki, T.; Tanaka, T. Substrate affects the initial attachment and subsequent behavior of human osteoblastic cells (Saos-2). Biomaterials 2001, 22, 2263-2271. [CrossRef]

10. Jemat, A.; Ghazali, M.J.; Razali, M.; Otsuka, Y. Surface modifications and their effects on titanium dental implants. BioMed Res. Int. 2015, 2015. [CrossRef] [PubMed]

11. Zhao, G.; Schwartz, Z.; Wieland, M.; Rupp, F.; Geis-Gerstorfer, J.; Cochran, D.L.; Boyan, B.D. High surface energy enhances cell response to titanium substrate microstructure. J. Biomed. Mater. Res. 2005, 74, 49-58. [CrossRef] [PubMed]

12. Li, Z.; Yi, J.; Huang, B.; Wu, X.; QIAO, W.; Luo, X.; Chen, Z. Ultraviolet irradiation enhanced bioactivity and biological response of mesenchymal stem cells on micro-arc oxidized titanium surfaces. Dent. Mater. J. 2015, 34, 135-147. [CrossRef] [PubMed]

13. Ogawa, T. Ultraviolet photofunctionalization of titanium implants. Int. J. Oral Maxillofac. Implant. 2014, 29. [CrossRef] [PubMed]

14. Shen, J.; Liu, J.; Chen, X.; Wang, X.; He, F.; Wang, H. The In Vivo Bone Response of Ultraviolet-Irradiated Titanium Implants Modified with Spontaneously Formed Nanostructures: An Experimental Study in Rabbits. Int. J. Oral Maxillofac. Implant. 2016, 31, 776-784. [CrossRef] [PubMed]

15. Areid, N.; Peltola, A.; Kangasniemi, I.; Ballo, A.; Närhi, T.O. Effect of ultraviolet light treatment on surface hydrophilicity and human gingival fibroblast response on nanostructured titanium surfaces. Clin. Exp. Dent. Res. 2018, 4, 78-85. [CrossRef] [PubMed]

16. Jimbo, R.; Ono, D.; Hirakawa, Y.; Odatsu, T.; Tanaka, T.; Sawase, T. Accelerated photo-induced hydrophilicity promotes osseointegration: An animal study. Clin. Implant Dent. Relat. Res. 2011, 13, 79-85. [CrossRef] [PubMed]

17. Lee, J.W.; Lim, H.C.; Lee, E.U.; Park, J.Y.; Lee, J.S.; Lee, D.W.; Jung, U.W.; Choi, S.H. Paracrine effect of the bone morphogeneticprotein-2 at the experimental site on healing of the adjacent control site: A study in the rabbit calvarial defect model. J. Periodontal Implant Sci. 2014, 44, 178-183. [CrossRef] [PubMed]

18. Sohn, J.Y.; Park, J.C.; Um, Y.J.; Jung, U.W.; Kim, C.S.; Cho, K.S.; Choi, S.H. Spontaneous healing capacity of rabbit cranial defects of various sizes. J. Periodontal Implant Sci. 2010, 40, 180-187. [CrossRef] [PubMed]

19. Lavenus, S.; Trichet, V.; Le Chevalier, S.; Hoornaert, A.; Louarn, G.; Layrolle, P. Cell differentiation and osseointegration influenced by nanoscale anodized titanium surfaces. Nanomedicine 2012, 7, 967-980. [CrossRef] [PubMed]

20. Tran, M.Q.; Yamaguchi, Y.; Yamatoya, K.; Horikoshi, S.; Nakata, K. Rewritable superhemophobic and superhemophilic wettability pattern based on titanium dioxide. Mater. Lett. 2018, 213, 51-53. [CrossRef]

21. Areid, N.; Kangasniemi, I.; Söderling, E.; Närhi, T.O. Ultraviolet photofunctionalization of nanostructured titanium surfaces enhances thrombogenicity and platelet response. J. Mater. Sci. Mater. Med. 2018, 29. [CrossRef] [PubMed]

22. Chen, J.; Yang, P.; Liao, Y.; Wang, J.; Chen, H.; Sun, H.; Huang, N. Effect of the duration of UV irradiation on the anticoagulant properties of titanium dioxide films. ACS Appl. Mater. Interfaces 2015, 7, 4423-4432. [CrossRef] [PubMed]

23. de Avila, E.D.; Lima, B.P.; Sekiya, T.; Torii, Y.; Ogawa, T.; Shi, W.; Lux, R. Effect of UV-photofunctionalization on oral bacterial attachment and biofilm formation to titanium implant material. Biomaterials 2015, 67, 84-92. [CrossRef] [PubMed]

24. Hori, N.; Ueno, T.; Suzuki, T.; Iwasa, F.; Yamada, M.; Att, W.; Okada, S.; Ohno, A.; Aita, H.; Kimoto, K. Ultraviolet light treatment for the restoration of age-related degradation of titanium bioactivity. Int. J. Oral Maxillofac. Implant. 2010, 25, 49-62. 
25. Ishijima, M.; Soltanzadeh, P.; Hirota, M.; Tsukimura, N.; SHIGAMI, T.; Ogawa, T. Enhancing osteoblast-affinity of titanium scaffolds for bone engineering by use of ultraviolet light treatment. Biomed. Res. 2015, 36, 55-62. [CrossRef] [PubMed]

26. Kim, S.-H.; Park, J.-H.; Kim, S.-J.; Kang, M.-Y.; Kang, M.-K. Rat Mastoid Bullae Obliteration with Hydroxyapatite: Histopathologic Results with Various Size of Hydroxyapatite. Korean J. Otorhinolaryngol. Head Neck Surg. 2010, 53. [CrossRef]

27. Chang, B.-S.; Hong, K.-S.; Youn, H.-J.; Ryu, H.-S.; Chung, S.-S.; Park, K.-W. Osteoconduction at porous hydroxyapatite with various pore configurations. Biomaterials 2000, 21, 1291-1298. [CrossRef]

(C) 2018 by the authors. Licensee MDPI, Basel, Switzerland. This article is an open access article distributed under the terms and conditions of the Creative Commons Attribution (CC BY) license (http:/ / creativecommons.org/licenses/by/4.0/). 